\title{
Factors affecting the successful implementation of Global Polio Eradication Initiative (GPEI) in low- and middle-ineome countries
}

\author{
Suleiman E Mshelia ${ }^{1}$, Chris Blackmore ${ }^{2}$, Rachel Archer ${ }^{2}$, Andrew Booth ${ }^{2}$
}

${ }^{1}$ Vom Christian Hospital, Vom-Manchok Road, Jos South, Plateau State, Nigeria
${ }^{2}$ School of Health and Related Research (ScHARR), University of Sheffield, Sheffield, England

$\mathrm{P}$ olio has become the major vaccine-preventable disease that has received the much-needed support for its complete eradication following the eradication of smallpox. Currently, the incidence of the disease has been reduced by $99 \%$ owing to the intensive efforts of the Global Polio Eradication Initiative (GPEI), which was instituted in 1988 to achieve complete eradication [1]. However, the persistence

The in-depth understanding and experiences of the beneficiaries of any public health intervention is key to the utilisation and improvement of the said service and herein lies the strength of qualitative research.

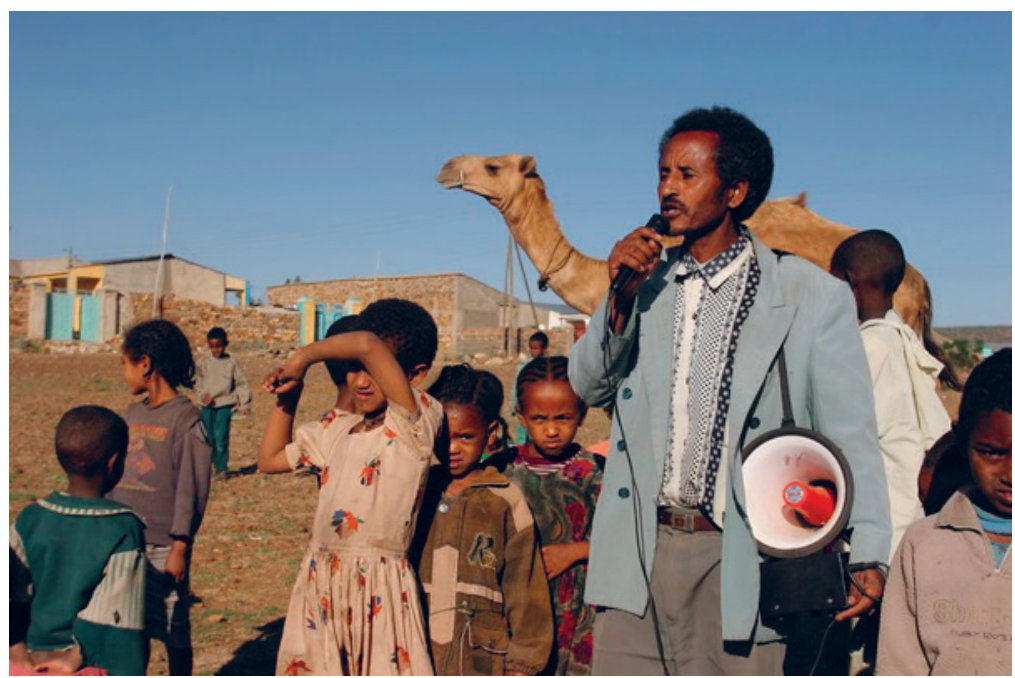

Photo: Man speaking about polio vaccination (by UNICEF Ethiopia, licensed under CC BY NC ND 2.0). Available: https://www.flickr.com/photos/86783452@N02. of the remaining $1 \%$ of polio in endemic countries of Pakistan, Afghanistan and Nigeria has remained a concern for stakeholders and policy makers [1] The current policy of GPEI is the Polio Endgame Strategy 2019-2023 [2] which is anchored by 3 main goals: (1) Eradication; (2) Integration; (3) Certification and Containment. Implementing this policy aims to ensure that no child gets paralysed anywhere again while other public health interventions continue to benefit from the polio eradication structure. A good example of this was in 2014 when the polio vaccination infrastructure was used to halt the Ebola outbreak in Nigeria [3]. Therefore, it is imperative to develop a body of evidence regarding the factors underpinning the eradication of polio to not only support the complete eradication but also to contribute to a robust framework for curtailing other vaccine-preventable diseases.

The value of Qualitative Evidence Synthesis (QES) methodology in improving complex health interventions, particularly in low- and middle-income countries, is increasingly being recognised. This methodology uniquely iden- 
The use of indigenous community volunteers can be instrumental in addressing contextual attitudinal barriers regarding vaccines and they can also play a crucial role in increasing vaccination uptake in conflict settings. tifies factors from qualitative research papers that can inform the improvement of health care interventions [4]. Experts argue that in-depth experiences of participants involved in any intervention are critical for the improvement of the said service [5] and this harnesses the strength of qualitative findings. In view of this, a QES regarding the successful implementation of GPEI in lowand middle-income countries was conducted by Mshelia et al. in 2019 [6], and this identified relevant barriers and facilitators regarding polio eradication.

The review used a best-fit framework of themes from Pakistan [7], which mapped themes both deductively and inductively. Generally, the findings from the review mapped well to the framework and new themes which emerged inductively include insecurity in high-risk polio areas, vaccine acceptability by caregivers, competing belief systems and cross-border polio surveillance (Table 1). A possible explanation of the new themes is that this review explored findings from different low- and middle-income countries and considered different contexts, which may have been different from that of Pakistan. Additionally, this review explored the perspective of caregivers, which greatly accounted for vaccine acceptability by caregivers (vaccine hesitancy). The significant rise in insurgency globally as from 2012 may possibly explain the new theme of insecurity in high-risk polio areas [8,9].

It is important to note that the new themes of vaccine hesitancy and insecurity in high-risk polio areas are the current major barriers faced by polio-endemic countries of Nigeria, Pakistan and Afghanistan [10]. Therefore, it is imperative to address these community-level factors as a path to achieving a polio-free world.

Insecurity impacts on vaccination activities either resulting in the mass movement of children leading to missing vaccination, inaccessibility or polio workers being targeted by insurgents. A recent report condemned the killing of a dedicated polio worker in Pakistan while undertaking polio vaccination activities [11]. A suggestion for the use of military personnel for vaccination activities was made from the experience of insecurity in the Lake Chad region [12] but experts argued that this method should be used with caution as it can be counterproductive by deepening false perceptions regarding the vaccine [10]. However, partnership with the military was seen to improve coverage of polio vaccination among insecure and hard-to-reach areas in Angola [13]. It was also found to address some issues of vaccine hesitancy.

Table 1. Factors affecting polio eradication in developing countries [6]

\begin{tabular}{|c|c|}
\hline THEMES & DESCRIPTION \\
\hline \multirow[t]{3}{*}{ Program resources and logistics } & Condition of cold chain in all aspects \\
\hline & Skills and authority in resource allocation and human resource management \\
\hline & Advocacy and communication resources \\
\hline Technical aspects & Skills and training among staff at all levels in all aspects of the program \\
\hline \multirow[t]{7}{*}{ Program operation, management and organization } & Availability of public health professionals and state of health service structure \\
\hline & Administrative issues including: \\
\hline & -Political influences and factors \\
\hline & -Factors in vaccination areas and the field program \\
\hline & -Immunization cards \\
\hline & Issues around access (availability of staff; waiting times etc) \\
\hline & Impact of positive/negative attitudes of health care staff \\
\hline \multirow[t]{2}{*}{ Monitoring, evaluation and feedback } & Reporting and monitoring systems \\
\hline & Decentralization of the health system \\
\hline Insecurity in high-risk polio areas & Safety issues in regions where polio exists \\
\hline \multirow[t]{6}{*}{ Vaccine acceptability by caregivers } & Perception of sterility induced by polio vaccine \\
\hline & Literacy status of caregivers \\
\hline & Influence of religion \\
\hline & Influence of frequent visits \\
\hline & Effectiveness of vaccination \\
\hline & Influence of vaccine side effects \\
\hline Competing belief systems & Eg, Islamic beliefs or traditional medicines \\
\hline Influence of community stakeholders & Community leaders as determinants of community vaccination \\
\hline The nature of disease & The understanding of polio as an influence \\
\hline Cross-border polio surveillance & Factors that determine polio spread between neighbouring countries \\
\hline
\end{tabular}


Further evidence demonstrates the use of community mobilisation using indigenous community members in conflict settings. This was a cluster randomised control trial that was carried out in conflict areas of Pakistan [14]. The findings buttressed the need to use local indigenous mobilisers and integrate polio vaccination as part of a maternal and child health package rather than a stand-alone specific polio campaign. This strategy significantly improved coverage in those settings. Further qualitative primary research should be undertaken to establish the relationship between insurgency and polio.

Another important community factor relates to vaccine resistance with underpinning factors as shown in Table 1. Even though this finding may take different forms, it buttresses the need to explore such factors contextually in areas of vaccine refusal, taking into account individual belief and value systems. This need underscores the fact that understanding the local perceptions of vaccine (not only polio) can be instrumental in mapping strategies to mitigate its refusal [15].

Nigeria is an important case study when it comes to addressing vaccine hesitance as remarkable success was achieved through the innovative use of Voluntary Community Mobilisers (VCM) [16]. These volunteers are a group of traditional and religious leaders that go around with the polio team combining the use of faith and science to educate communities. This builds trust within families concerning the vaccines, thereby increasing its uptake. Most importantly, the volunteers are well-known in the regions and thus leverage on previous trust. This is an important way to address vaccine hesitancy.

\section{WAY FORWARD}

Immunisation is key to universal health coverage and that immunisation coverage is a valuable indicator of the strength of services delivered by any health system [17]. Since vaccination is a complex intervention, low- and middle-income countries need to adopt a broad perspective in addressing the issues influencing its success in their respective countries. Therefore, exploring the perspective of not only stakeholders but also of parents and caregivers for every given context will be instrumental to the improvement of polio eradication programmes. Stakeholder involvement will thus facilitate the delivery, and consequent success, of other vaccination programs.

Funding: There was no funding in any form for this research.

Authorship contributions: SEM wrote the initial draft with contributions by CB and AB. RA gave overall inputs. All authors contributed to the general editing of the final manuscript.

Competing interests: The authors completed the ICMJE Unified Competing Interest form (available upon request from the corresponding author), and declare no conflicts of interest.

1 World Health Organization. Poliomyelitis. 2017. Available: http://www.who.int/mediacentre/factsheets/fs114/en/. Accessed: 15 August 2017.

2 World Health Organization. Polio Endgame Strategy 2019- 2023: Eradication, Integration, Containment and Certification 2019 Available: http://polioeradication.org/who-we-are/polio-endgame-strategy-2019-2023/. Accessed: 15 November 2019.

3 Global polio eradication Initiative. Polio Today; 2019. Available from: http://polioeradication.org/wp-content/uploads/2019/03/GPEI-Fact-Sheet-March-2019-20190315.pdf. Accessed: 15 November 2019

4 Langlois EV, Tunçalp Ö, Norris SL, Askew I, Ghaffar A. Qualitative evidence to improve guidelines and health decision-making. Bull World Health Organ. 2018;96:79. Medline:29403107 doi:10.2471/BLT.17.206540

5 Booth A, Noyes J, Flemming K, Gerhardus A, Wahlster P, Van Der Wilt GJ, et al. Guidance on choosing qualitative evidence synthesis methods for use in health technology assessments of complex interventions. InIntegrate-HTA 2016. Available: https://www.researchgate.net/profile/Andrew_Booth/publication/294581344_Guidance_on_choosing_qualitative_ evidence_synthesis_methods_for_use_in_health_technology_assessments_of_complex_interventions/ links/56c21c4208ae44da37ff582c.pdf. Accessed: 15 June 2017.

6 Mshelia SE, Blackmore C, Archer R, Booth A. Factors influencing the implementation of Global Polio Eradication Initiative in Low- and Middle-Income Countries: A qualitative evidence synthesis. J Glob Health Rep. 2019;3:e2019073. doi:10.29392//001c.11982

7 Mushtaq MU, Shahid U, Majrooh MA, Shad MA, Siddiqui AM, Akram J. From their own perspective-constraints in the Polio Eradication Initiative: perceptions of health workers and managers in a district of Pakistan's Punjab province. BMC Int Health Hum Rights. 2010;10:22. Medline:20731832 doi:10.1186/1472-698X-10-22 
8 Garon JR, Orenstein WA. Overcoming barriers to polio eradication in conflict areas. Lancet Infect Dis. 2015;15:1122-4. Medline:26179315 doi:10.1016/\$1473-3099(15)00008-0

9 World Health Organisation. Polio Endgame Strategy 2019-2023. World Health Organ. 2019. Available at: http://polioeradication.org/wp-content/uploads/2019/06/english-polio-endgame-strategy.pdf. Accessed: 15 November 2019.

10 Kennedy J, McKee M, King L. Islamist insurgency and the war against polio: A cross-national analysis of the political determinants of polio. Global Health. 2015;11:40. Medline:26420386 doi:10.1186/s12992-015-0123-y

11 World Health Organisation. WHO EMRO | WHO condemns killing of polio worker in Pakistan | Pakistan-news | Pakistan. World Health Organ. 2019. Available: http://www.emro.who.int/pak/pakistan-news/who-condemns-killing-of-polio-worker-in-pakistan.html. Accessed: 19 April 2019.

12 Bigna JJ. Polio eradication efforts in regions of geopolitical strife: the Boko Haram threat to efforts in sub-Saharan Africa. Afr Health Sci. 2016;16:584-7. Medline:27605975 doi:10.4314/ahs.v16i2.28

13 Fekadu L, Okeibunor J, Nsubuga P, Kipela JM, Mkanda P, Mihigo R. Reaching the unreached with polio vaccine and other child survival interventions through partnership with military in Angola. Vaccine. 2016;34:5155-8. Medline:27354259 doi:10.1016/j.vaccine.2016.05.069

14 Habib MA, Soofi S, Cousens S, Anwar S. ul Haque N, Ahmed I, Ali N, Tahir R, Bhutta ZA. Community engagement and integrated health and polio immunisation campaigns in conflict-affected areas of Pakistan: a cluster randomised controlled trial. Lancet Glob Health. 2017;5:e593-603. Medline:28495264 doi:10.1016/S2214-109X(17)30184-5

15 Widdus R, Larson H. Vaccine mandates, public trust, and vaccine confidence: understanding perceptions is important. J Public Health Policy. 2018;2:170-2. Medline:29568036 doi:10.1057/s41271-017-0117-5

16 United Nations Foundation. Innovation in action: fighting polio in Nigeria. 2019. New York. United Nations foundation. Available: https://unfoundation.org/blog/post/innovation-in-action-fighting-polio-in-nigeria/. Accessed: 20 November 2019.

17 Berkley S, Gitahi G. Improving vaccination coverage is key to universal health coverage. 2019. SciDev.Net Available: https://www.scidev.net/sub-saharan-africa/medicine/opinion/child-immunisation-as-key-pathway-to-health-for-all.html. Accessed: 26 April 2019.

\section{Correspondence to:}

Dr Suleiman E. Mshelia, MBBS, MPH (Sheffield), DiPM (UK)

Vom Christian Hospital

P.M.B 06

Vom-Manchok Road

Jos South

Plateau State

Nigeria

suleimanmshelia@gmail.com 